\title{
USG Liver examination of Tahfiz Quran Primary School students in Berastagi
}

\author{
Elvita Rahmi Daulay ${ }^{1 *}$, Mohammad Rhiza Z. Tala ${ }^{2}$ \\ ${ }^{1}$ Department of Radiology, Faculty of Medicine, Universitas Sumatera Utara \\ ${ }^{2}$ Department of Obstetry and Gynecology, Faculty of Medicine, Universitas Sumatera Utara \\ *Email: elvitarahmi.daulay@usu.ac.id
}

\begin{abstract}
The Liver is the largest solid organ in the human body and has many roles in maintaining a healthy body. Non-alcoholic Fatty Liver Disease (NAFLD) is a fatty liver without being accompanied by the consumption of alcohol. NAFLD is a condition that is often found in children. The majority of patients with NAFLD are asymptomatic. The diagnosis of NAFLD is usually made through imaging the liver or abnormal liver function with the presence of metabolic syndrome and or overweight. Ultrasound has high sensitivity and specificity in diagnosing NAFLD into an imaging technique that is widely used in cases with fatty liver. This community service is done to find out about the liver health of Tahfiz Quran Primary School students in Berastagi. It is also an effort to screening and early detection of liver health problems in those students. It also aims to raise awareness of heart health among students, teachers, and parents. Ultrasound liver examination of the 59 Tahfiz Quran Primary School students. Educational activities also done to educate the students about liver health. Out of 59 students, 10 students (16.9\%) had mild fatty liver, 1 student (1.7\%) had a calcified liver, and 36 students $(61.0 \%)$ had ascites. Fatty liver was found among the students also the majority of the students had ascites.
\end{abstract}

\section{Keywords: Liver, Ultrasound, Fatty Liver}

\section{INTRODUCTION}

The liver is the largest solid organ in the human body (Hansen, 2017). A healthy liver is brown with a smooth surface. The liver takes up to $2 \%$ of the total body weight of adults with approximate 1400 grams and 1800 grams in women in men (Sibulesky, 2013). It located in the upper right quadrant of the abdominal cavity under the right hemidiaphragm and protected by the rib (Abdel-Misih and Bloomston, 2010). Several ligaments associated with the liver are falciform ligament, the ligament teres hepatitis, and coronary ligament. Falsiformis ligaments anatomically divide the liver into a large right lobe and a smaller left lobe. This ligament attaches the liver to the anterior abdominal wall. Teres ligament of the liver in the form of thickening the lower limit of the ligaments falsiformis a remnant of the fetal umbilical vein. The liver is attached to the inferior surface of the diaphragm by the coronary ligament. The liver has several essential functions, especially in the metabolism of nutrients (Ozougwu, 2017). Liver function including the secretion of bile which is vital in the emulsification and absorption of fat, metabolism of bilirubin, synthesis of factors coagulant, nutrient metabolism, detoxification metabolite, storage of vitamins and minerals and function in the immune system (Sherwood et al., 2012, Ozougwu, 2017, Hall, 2010).

Non-alcoholic Fatty Liver Disease (NAFLD) is a fatty liver without being accompanied by the consumption of alcohol. The disease is often found in patients 40-50 years of age and younger age when accompanied by metabolic syndrome. NAFLD is a condition that is often found in children (Feldstein, 2013). The prevalence of NAFLD increases when childhood ranging from $1 \%$ in children aged $2-4$ years up to $13-17 \%$ in their late teens (Adams, 2013). NAFLD has a higher prevalence in males than females (Chowdhury and Younossi, 2016; Farrell et al., 2013). 
NAFLD has a moderately high prevalence of $20-30 \%$. In the Asia-Pacific area, the prevalence of NAFLD has $5-40 \%$ of the population in general. It presumably due to the high prevalence of the risk factors in the Asia Pacific area (Kao et al., 2013). Identification of the disease is important due to high mortality (Kim et al., 2016). NFALD associated with obesity, dyslipidemia, type 2 diabetes, and increased levels of serum fatty acid (Yang et al., 2014). The disease has a relationship with the risk of cardiovascular disease and a poor quality of life than the general population and patients with other chronic diseases (Targher, 2013; Newton and Frith, 2013).

The majority of patients with NAFLD are asymptomatic. The symptoms appear in patients with NAFLD are tired as a significant symptom in this case accompanied by sleep disorders such as excessive daytime sleepiness. Other symptoms include autonomic dysfunction (syncope and dizziness), cognitive disorders, and depression (Newton and Frith, 2013; Mashav and Shibolet, 2015). In children, symptoms of NAFLD are in the form of fatigue and discomfort in the upper right abdomen or around the abdomen. Children with NAFLD is usually associated with obesity and insulin resistance, impaired glucose tolerance, type 2 diabetes, and dyslipidemia (Feldstein, 2013).

The diagnosis of NAFLD is usually made through imaging the liver or abnormal liver function with the presence of metabolic syndrome and or without overweight (Chitturi and Farrell, 2013). In children, the diagnosis is obtained by an increase in serum aminotransferase, ultrasound, and liver biopsy, although rarely, is the standard gold diagnosis of NAFLD. Liver biopsies are invasive and cause significant complications such as bleeding (Feldstein, 2013).

Liver biopsy is considered the gold standard of diagnosis of NAFLD. However, liver biopsy is limited clinical use in children due to its invasion. Non-invasive diagnostic methods such as imaging, biomarkers of inflammation, oxidative stress, apoptosis of the liver and liver fibrosis, and liver fibrosis score may be useful to address these shortcomings. Although non-invasive methods have not been widely used or validated in pediatric NAFLD, some of them may be applied to detect liver steatosis and even predict liver fibrosis in children with NAFLD (Yang, 2013).

Ultrasound is a non-invasive diagnostic imaging technique that uses high-frequency sound waves. The tools used are an ultrasound machine with a transducer which acts to transmit and receive sound waves from several tissues in the body (Chen et al., 2010). The transducer will be driven by the radiologist on the surface of a patient's body, which had previously been smeared with gel. The gel will form an acoustic seal between the transducer and the skin so that the transmission of sound is better and produce better images. The transducer can transmit and receive high-frequency sound waves that transmit or reflect structures in the body. The sound waves are returned depending on the intensity or called echogenicity and the time required by the waves to be reflected (Singh et al., 2014).

Echogenecity of each different tissue is displayed differently on the ultrasound monitor. Abdominal fat has a high echogenicity compared to other tissues. The image that appears on the ultrasound monitor looks whiter and is described as an increase in eco or hyperechoic texture. Tissue that reflects low echogenicity appears darker and is described as a reduction or hypoechoic texture. The intensity of the echo could help differentiate organs and determine the pathological organ state (Singh et al., 2014).

The liver has homogeneous parenchyma. The liver is the most echogenic organ on ultrasound after the pancreas (Chen et al., 2010). Healthy liver on ultrasound examination showed a smooth surface that bordered by the image of the blood vessels. Doppler ultrasound examination is used to display a picture of the heart blood vessels.

USG is an imaging technique that is widely used in cases with fatty liver. The sensitivity and specificity of this modality in the detection of fatty liver are $60-94 \%$ and $88-95 \%$ (Mashav and Shibolet, 2015). In ultrasound, the fatty liver showed us rather hyperechoic liver parenchyma compared to the blurred kidneys, blood vessels and bile ducts, bad liver field visualization, and opaque diaphragm. CT (Computed Tomography) scan non-contrast produce a darker picture than the liver spleen as well as MRI (Magnetic Resonance Imaging) (Yokoo et al., 2013; Loomba, 2018).

A liver ultrasound examination and assessed the presence of the free fluid in the abdominal and pleural cavity for Tahfiz Quran Primary School students was done as the community service. The results of the ultrasound examination of the students were recorded and presented in this paper. This 
examination is also intended as a means of careful medical examination and early detection of health problems on the students. Counseling about the liver and the diseases was also done to improve the knowledge of students.

\section{METHOD}

The implementation method offered from the community service program is divided into several stages, such as the survey of the location, counseling, and careful examination using ultrasound to the students.

The counseling contained information about liver health and the introduction of the ultrasound examination. The students underwent a liver ultrasound examination using a portable ultrasonography device. The liver was assessed alongside the presence of free fluid in the abdominal and pleural cavity. The liver ultrasound examination performed to obtain the distribution of examination results of the students.

\section{RESULTS AND DISCUSSION}

Community service for ultrasonography (USG) was held in Tahfiz Quran Primary School, Berastagi with the 3rd graders as the participant. Characteristics of Tahfiz Quran Primary School students who participated in community service could be seen in the following table:

\begin{tabular}{lll}
\hline Characteristics & $\mathrm{n}$ & $\%$ \\
\hline Gender & & \\
Male & 32 & 54.2 \\
Female & 27 & 45.8 \\
\hline
\end{tabular}

Table 1. Distribution based on results of liver Ultrasound Tahfiz Quran Students

Based on Table 1 shows that out of 59 students of Tahfiz Quran Primary School who participated in community service, the male students were dominant as many as 32 people $(54.2 \%)$, followed by the female as many as 27 people $(45.8 \%)$.

\begin{tabular}{lcc}
\hline Examination's Result & $\mathrm{N}$ & $\%$ \\
\hline Liver & & \\
$\quad$ Normal & 48 & 81,4 \\
Mild fatty liver & 10 & 16,9 \\
Calcification & 1 & 1,7 \\
\hline Free fluid & & \\
$\quad$ No free fluid & 19 & 32,2 \\
Ascites & 36 & 61,0 \\
$\quad$ Pleural effusion & 4 & 6,8 \\
\hline
\end{tabular}

Table 2. Distribution based on results of liver Ultrasound Tahfiz Quran Students

Table 2 showed out of 59 students, 48 students (81.4\%) were found with a normal liver sonogram. Liver abnormalities found during the ultrasound is a mild fatty liver, as many as 10 students $(16.9 \%)$ and calcification of the liver as much as 1 student (1.7\%). Ascites is found in $36(61.0 \%)$ male and female students of the community service participants, pleural effusion was found in 4 students $(6.8 \%)$.

\begin{tabular}{lll}
\hline Mild fatty liver & $\mathrm{N}$ & $\%$ \\
\hline Gender & & \\
Male & 1 & 10 \\
Female & 9 & 90 \\
\hline
\end{tabular}

Table 3. Distribution of Tahfiz Quran Primary School students with mild fatty liver by gender 
Based on Table 3, it was found that out of 10 students, mild fatty liver is more common in female as much as 9 people $(90 \%)$ than in male by 1 person $(10 \%)$.

\begin{tabular}{lcc}
\hline Calcification of Liver & $\mathrm{N}$ & $\%$ \\
\hline Gender & & \\
Male & 0 & 0 \\
Female & 1 & 100 \\
\hline
\end{tabular}

Table 4. Distribution of Tahfiz Quran Primary School students with clacification of liver by gender

It shows that out of 59 participants of community service, there is $1(100 \%)$ with the results of an ultrasound examination showed calcification in the liver with the female gender.

\begin{tabular}{llc}
\hline Ascites & $\mathrm{N}$ & $\%$ \\
\hline Gender & & \\
Male & 20 & 55,6 \\
Female & 16 & 44,4 \\
\hline
\end{tabular}

Table 5. Distribution of Tahfiz Quran Primary School students with ascites by gender

In Table 5 show that out of 36 male and female student participants who experienced ascites, male are more often found to experience ascites as many as 20 students (55.6\%) than the female with $16(44.4 \%)$ students.

\begin{tabular}{lcc}
\hline Pleural effusion & $\mathrm{N}$ & $\%$ \\
\hline Gender & & \\
Male & 1 & 100 \\
Female & 0 & 0 \\
\hline
\end{tabular}

Table 6. Distribution of Tahfiz Quran Primary School students with pleural effusion by gender

Based on Table 6, it was found that students who experienced a pleural effusion 4 out of $4(100 \%)$ students were male gender.

Counseling is done to all male and female students of 3rd graders Tahfiz Quran as a participant in this community service. Counseling regarding the health and disease of the liver. Education carried out to identify the causes and characteristics and the prevention of disease in the liver. The level of understanding of male and female students was evaluated using questionnaires given before and after the extension services. There are 38 students with the number of correct answers $100 \%, 6$ students with the number of correct answers $90 \%, 9$ with the number of correct answers to $80 \%$, and 3 students with the number of correct answers $70 \%$ and $60 \%$.

The reported prevalence of NAFLD varies widely depending on the population studied and the definition used. NAFLD incidence rate estimates, respectively for Asia and Israel were 52.34 per 1,000 and 28.01 per 1,000 people (Younossi et al., 2016).

One study from January 2011 to August 2013, 2,105 patients were undergoing a medical check-up in Charitas Hospital, Palembang with the liver ultrasound, there were $166(7.9 \%)$ patients diagnosed as NAFLD. The majority of the patients diagnosed as NAFLD $(81.1 \%)$ were male, which was more common to suffer from NAFLD than female patients (Cahyono et al., 2013).

Fatty liver is a consequence of the digestion of ethanol in large quantities. Alcohol causes a decrease in oxidation and fatty acid synthesis, causing a buildup of fatty acids. The duration of alcohol consumption at most in patients with fatty liver was 20 years old. Genetic influence on a person is increasing the risk of experiencing a fatty liver due to alcohol (Lazo \& Mitchell, 2016).

Symptoms of fatty liver due to alcohol appear after liver disease has become severe and threaten lives. The physical examination which found in this disorder is ascites, cutaneous telangiectasia, gynecomastia, hepatomegaly, jaundice, malnutrition, and hepatomegaly. Liver function tests such as 
aspartate aminotransferase (AST) and alanine aminotransferase (ALT) were conducted to assist in diagnosis (Cheong et al., 2016).

The consumption of alcohol could also accompany a fatty liver without the so-called non-alcoholic fatty liver disease. Non-alcoholics have a sense of alcohol consumption that does not exceed 70 grams of ethanol per week in women and not more than 140 grams of ethanol per week in men. These abnormalities are often found in patients aged 40-50 years. Younger age was found when patients have metabolic syndrome. Men have more prevalence of this disorder than women. Almost $90 \%$ of patients with non-alcoholic fatty liver are obesity (Chowdury and Younossi, 2016; Farrell et al., 2013).

Accumulation of fat in the liver is closely related to the body's metabolic problems. Metabolic factors, such as diabetes, obesity, and hypertension, may affect the state of the liver tissue that can eventually lead to a buildup of fat in the liver (Calzadila, 2016).

NAFLD if left untreated, could turn into cirrhosis of the liver (Byrne \& Targher, 2015). NAFLD can also develop into extrahepatic chronic diseases such as cardiovascular disease and chronic renal failure (Adams et al., 2017).

In tackling the problem of NAFLD is the main thing to do is to lose weight and protect hepatocytes (Hattar et al., 2011). In addition to diet and exercise, other things could be implemented as the handling of the case, such as insulin sensitizers administration, ursodeoxycholic acid, and surgery (Journalists et al., 2012). Giving antioxidants such as vitamin E, vitamin C, betaine, N-acetylcysteine, Probucol, and silymarin in NAFLD cases showed improvement of liver function and histopathologic features. (Journalists et al., 2014).

A variety of pathological abnormalities could lead to calcification of the liver. Imaging findings in conjunction with clinical presentation, laboratory values, and a tissue sample could be used in formulating a treatment plan for patients with liver mass calcification (Sharma and Dev, 2019). Hepatic calcification is usually associated with infectious, vascular, or neoplastic processes in the liver.

In this case, students were found mostly experienced ascites. Peritoneal fluid is a liquid made in the abdominal cavity, which lubricates the surface of the tissue that lines the abdominal wall and pelvic cavity. It covers most of the organs in the abdomen. The increasing of the volume of peritoneal fluid called ascites. Ascites itself is a pathological buildup of fluid in the peritoneal cavity (Lane et al., 2015).

Ascites generally occur when there is a disturbance or problems in a person's liver so that the liver function is inadequate. The liquid will fill the cavity between the stomach or abdominal organs commonly called the abdomen or peritoneal cavity. Ascites has many causes, including liver disorders, infections, malignancies, kidney disorders, and malnutrition (Karnsakul et al., 2017).

Ascites can occur in a normal peritoneum or abnormal peritoneum. If the peritoneum is normal (no abnormality), then the cause of ascites is portal hypertension and hypoalbuminemia. While on the peritoneal pathological abnormalities, ascites causes include infection (bacterial peritonitis / TB / fungal, HIV-associated peritonitis, and other), malignancy/carcinoma peritoneal, and other. The development of ascites is the final consequence of a series of anatomic, pathophysiologic, and biochemical abnormalities. The same principles govern the formation of ascites as edema formation at other sites: net capillary permeability and the hydraulic and oncotic pressure gradients (Such and Runyon, 2016).

Ascites by the numbers divided into three levels/grades. Grade I (minimal) is that ascites in minimal quantities that only be detected via ultrasound. Grade II (moderate), the ascites was seen as abdominal distension are symmetrical. Grade III (large), the ascites is in large amounts to pose a very real abdominal distension (EASL, 2010).

Ascites is generally treated as the underlying cause sought, to prevent complications, relieve symptoms, and prevent further progression. In people with mild ascites, therapy is usually as an outpatient. The goal is a weight loss of no more than $1.0 \mathrm{~kg}$ /day for people with both ascites and peripheral edema and no more than $0.5 \mathrm{~kg} /$ day for people with ascites alone. Treatment of ascites in children depends on identifying and resolving underlying etiology or mechanism that causes ascites itself. In-depth clinical examination and laboratory examination is the first step in the diagnosis of ascites. Furthermore, ascites could be diagnosed using imaging examination, one using ultrasound. 
Examination of liver biopsy also has a vital role in deciding causes ascites derived from the liver (Lane et al., 2015).

If not appropriately managed, ascites could become peritonitis (a life-threatening), hepatorenal syndrome (renal vasoconstriction due to the activity of salt and fluid withdrawal from the kidney), malnutrition-hepatic encephalopathy, and other complications associated with the disease cause of ascites (EASL, 2010).

The pleura is the outer part of the lung and surrounds the lungs. Pleural is formed by fibrous connective tissue in which there are many lymph capillaries and blood capillaries and small nerve fibers. Pleural also formed by cells (mainly fibroblasts and macrophages). A layer of mesotel coats lung pleura. The pleura is a thin membrane, smooth and slick wrapped around the anterior thoracic wall and the superior surface of the diaphragm. This thin layer containing collagen and elastic tissue (Sylvia and Lorraine, 2009).

There are two kinds of pleura, namely parietal pleura, which is lining the thoracic or chest cavity and visceral pleura, which is lining the lungs. Both are united at the hilum of the lung. Between those pleural, there is a room called the pleura space, which contains a small amount of fluid that lubricates the surface and allows both moved freely during ventilation. The liquid is called pleural fluid which located between the lung and thorax. The average amount is $10-20 \mathrm{cc}$ of pleural fluid in adults. Usually, these two pleural layers are separated by a bit of air and liquid inside, like oil on the engine pleural fluid serves as a lubricant to help smooth the movement of the lungs inflate and deflate while breathing time. However, when there is a buildup of excess fluid in the pleura, the fluid will urge the lung inwards so that the movement of the lungs is limited (Hood, 2010).

Pleural effusion is a term used to denote the accumulation of fluid in the pleural cavity. Pleural effusion, as a primary disease process is rare but usually occurs secondary to another disease. The effusion may be a clear liquid, which may be a transudate, or it may be blood or pus (Harjanto et al., 2018).

Based on the location of the liquid formed, pleural effusion divided into unilateral and bilateral. Unilateral effusion has no specific connection with the cause of disease, but bilateral effusions are often found in disease: congestive heart failure, nephrotic syndrome, ascites, pulmonary infarction, systemic lupus erythematosus, tumor and tuberculosis (Sylvia and Lorraine, 2009). Pleural effusion in children commonly caused by a secondary infection, whereas in adults caused by congestive heart failure and malignancy.

Treatment depends on the cause of a pleural effusion. The principle of treatment of pleural effusion is a discharge and stop so that the liquid is not produced anymore. Therefore, it is important to know the underlying causes for later therapy according to the cause and severity. Therapeutic aspiration may be sufficient; on a broader effusion required interval intercostal (between the ribs) to remove fluid (such as a pigtail or surgery). When using a chest tube, it is important to ensure the hose is clogged or not. A clogged chest tube will cause the residual liquid left inside the pleural cavity when the tool is removed. This fluid potentially causes complications such as hypoxia due to lung collapse by fluid, or pleural fibrothorax in case of injury. In surgery, it also included chest tube pleurodesis for action (Carter et al., 2010). The diuretic treatment has proven effective in cases with ascites and pleural effusion (Ağbaş, 2019).

\section{CONCLUSION}

Out of 59 students, 10 students (16.9\%) had mild fatty liver, and $1(1.7 \%)$ student had a calcified heart, and 36 students $(61.0 \%)$ students had ascites.

\section{ACKNOWLEDGMENT}

The author wants to express big gratitude towards Lembaga Pengabdian Masyarakat Universitas Sumatera Utara for the financial support for this community service, under the TALENTA Project 2019, No. 327/UN5.2.3.2.1/PPM/2019. 
Also thanks for the hard work of the committee team that consists of Wina Viqa Sari, Raudah Putri Syari, Sinta Azhary Ginting, Roni Hikmah Ramadhan, Fahrur Rozi and all the Radiologist residents of H. Adam Malik Hospital that have been participated in this event.

\section{REFERENCES}

Abdel-Misih, S. R., Bloomston, M. 2010. Liver anatomy. Surgical Clinics, 90, 643-653.

Aams, L. A. 2013. NAFLD in the Community. Non-Alcoholic Fatty Liver Disease: A Practical Guide, 17-26.

Adams, L. A., Anstee, Q. M., Tilg, H., \& Targher, G. 2017. Non-alcoholic fatty liver disease and its relationship with cardiovascular disease and other extrahepatic diseases. Gut, 66(6), 1138-1153.

Ağbaş, A., Aksu, B., Doğan, G., İkizceli, T., Selçuk, H. N. D., \& Elevli, M. 2019. A child with bilateral multiple renal cysts presenting with ascites and pleural effusion: Answers. Pediatric Nephrology, $1-2$.

Byrne, C. D., \& Targher, G. 2015. NAFLD: a multisystem disease. Journal of hepatology, 62(1), S47S64.

Cahyono, S. B., Bayupurnama, P., Ratnasari, N., Maduseno, S., \& Nurdjanah, S. 2013. Ultrasounddiagnosed non-alcoholic fatty liver disease among medical check up patients. Indonesian Journal of Gastroenterology, Hepatology, and Digestive Endoscopy, 14(3), 145-149.

Calzadilla Bertot, L., \& Adams, L. 2016. The natural course of non-alcoholic fatty liver disease. International journal of molecular sciences, 17(5), 774.

Carter, E., Waldhausen, J., Zhang, W., Hoffman, L., \& Redding, G. 2010. Management of children with empyema: pleural drainage is not always necessary. Pediatric pulmonology, 45(5), 475-480.

Chen MY, Pope TL, Ott DJ. 2010. Basic radiology. McGraw Hill Professional

Cheong J, Stein E, Bataller R. 2016. Diagnostic approaches and clinical end points of treatment in alcoholic liver disease. Alcoholic and Non-Alcoholic Fatty Liver Disease. Springer, 195-209.

Chitturi, S., Farrell, G. C. 2013. A primary care perspective of fatty liver: diagnosis, management, prescribing, and when to refer. Non-Alcoholic Fatty Liver, 84.

Chowdhury, A., Younossi, Z. M. 2016. Global epidemiology and risk factors for nonalcoholic fatty liver disease. Alcoholic and Non-Alcoholic Fatty Liver Disease. Springer.

European Association for the Study of the Liver (EASL). 2010. EASL clinical practice guidelines on the management of ascites, spontaneous bacterial peritonitis, and hepatorenal syndrome in cirrhosis. Journal of Hepatology vol. 53:397-417

Farrell, G. C., Mccullough, A. J., Day, C. P. 2013. What is non-alcoholic fatty liver disease (NAFLD), and why is it important? Non-alcoholic Fatty Liver Disease: a Practical Guide. J. Wiley and Sons, Chichester, West Sussex, UK.

Feldstein, A. E., Alkhouri, N., De Vito, R., Alisi, A., Lopez, R., \& Nobili, V. 2013. Serum cytokeratin18 fragment levels are useful biomarkers for nonalcoholic steatohepatitis in children. The American journal of gastroenterology, 108(9), 1526.

Hall, J. E. 2010. Guyton and Hall Textbook of Medical Physiology. E-Book: with STUDENT CONSULT Online Access, Elsevier Health Sciences.

Hansen, J. T. 2017. Netter's Clinical Anatomy E-Book. Elsevier Health Sciences.

Hattar LN, Wilson TA, Tabotabo LA, Smith EO, Abrams SH. Physical activity and nutrition attitudes in obese Hispanic children with non-alcoholic steatohepatitis. World J Gastroenterol 2011; 17(39): 4396-403.

Harjanto, A. R., Nurdin, F., \& Rahmanoe, M. 2018. Efusi Pleura Sinistra Masif Et Causa TB pada Anak. Jurnal Majority, 7(3), 152-157.

Hickman, I. J., Macdonald, G. A., Byrne, N. M. 2013. Physical activity and cardiovascular fitness in patients with NAFLD: clinical importance and therapeutic implications. Non-Alcoholic Fatty Liver Disease. 132-148. 
Hood, A. H., Abdul, M. 2010. Dasar-dasar ilmu Penyakit Paru. Airlangga University Press. SurabayaIndonesia.

Jurnalis, Y. D., Delfican, D., \& Sayoeti, Y. 2012. Penyakit perlemakan hati non alkoholik pada anak. Majalah Kedokteran Andalas, 36(2), 121-131.

Jurnalis, Y. D., Sayoeti, Y., \& Elfitrimelly, E. 2014. Peran Antioksidan pada Non Alcoholic Fatty Liver Disease (NAFLD). Jurnal Kesehatan Andalas, 3(1).

Karnsakul, W., Ingviya, T., Seaberg, E., Laengvejkal, P., Imteyaz, H., Vasilescu, A., ... \& Scheimann, A. O. 2017. Ascites in Children: A Single-Center Experience of 27 Years. Journal of pediatric gastroenterology and nutrition, 64(1), 83-88.

Kao, J. H., Amarapurkar, D. \&amp; FAN, J. G. 2013. NAFLD in Chinese and South Asian people. Non-Alcoholic Fatty Liver, 206.

Kim, D., Chung, G. E., Kwak, M. S., Seo, H. B., Kang, J. H., Kim, W., ... \& Kim, C. Y. 2016. Body fat distribution and risk of incident and regressed nonalcoholic fatty liver disease. Clinical Gastroenterology and Hepatology, 14(1), 132-138.

Lane, E. R., Hsu, E. K., \& Murray, K. F. 2015. Management of ascites in children. Expert review of gastroenterology \& hepatology, 9(10), 1281-1292.

Lazo M, Mitchell MC. 2016. Epidemiology and risk factors for alcoholic liver disease. Alcoholic and Non-Alcoholic Fatty Liver Disease. Springer, 1-20.

Loomba, R. 2018. Role of imaging-based biomarkers in NAFLD: Recent advances in clinical application and future research directions. Journal of hepatology, 68, 296-304.

Mahav, N., Shibolet, O. 2015. Clinical Aspects of Nonalcoholic Fatty Liver Disease. Liver Metabolism and Fatty Liver Disease. CRC Press, Boca Raton, 13.

Newton, J. L., Frith, J. 2013. Fatigue, quality of life, and psychosocial issues for people with NAFLD. Non-Alcoholic Fatty Liver. 122.

Ozougwu, J. 2017. Physiology of the liver. International Journal of Research in Pharmacy and Biosciences, 4, 13-24

Sharma, M., \& Dev, M. 2019. Calcified liver lesions and mimics on CT. American Journal of Roentgenology, 212(3), W98-W98.

Sherwood, L., Klandorf, H., Yancey, P. 2012. Animal physiology: from genes to organisms, Cengage Learning.

Singh H, Neutze JA, Enterline JR. 2014 Radiology Fundamentals: Introduction to Imaging \& Technology. Springer.

Sibulesky, L. 2013. Normal liver anatomy. Clinical liver disease, 2, S1.

Such, J., \& Runyon, B. A. 2016. Pathogenesis of ascites in patients with cirrhosis. Waltham. Accessed, 5.

Sylvia A, Lorraine M. 2009. Patofisiologi konsep Klinis Proses-proses Penyakit. ECG. JakartaIndonesia

Targher, G. 2013. NAFLD and cardiovascular risk factors: implications for vascular disease. NonAlcoholic Fatty Liver, 71.

Yang, H. R. 2013. Noninvasive diagnosis of pediatric nonalcoholic fatty liver disease. Korean journal of pediatrics, 56(2), 45 .

Yang, W., Huang, H., Wang, Y., Yu, X. \&amp; Yang, Z. 2014. High red blood cell distribution width is closely associated with nonalcoholic fatty liver disease. European journal of gastroenterology \& hepatology, 26, 174-178.

Yokoo, T., Tang, A. \&amp; Sirlin, C. B. 2013. Imaging of NAFLD. Non-Alcoholic Fatty Liver Disease: A Practical Guide, 93-111.

Younossi, Z. M., Koenig, A. B., Abdelatif, D., Fazel, Y., Henry, L., \& Wymer, M. 2016. Global epidemiology of nonalcoholic fatty liver disease-meta-analytic assessment of prevalence, incidence, and outcomes. Hepatology, 64(1), 73-84. 